\title{
Dental age assessment of North Indian origin children using Nolla's method in mandibular second molar
}

\author{
Harsh Vijay Singh, Namita Kalra* ${ }^{*}$, Rishi Tyagi and Amit Khatri
}

\begin{abstract}
Background: A cross-sectional study was done on 900 children of North Indian origin, (male $=458$; female $=442$ ) aged 10 to 16 years. Digital radiovisiography of permanent mandibular second molar was chosen over higher radiation extra oral projections used for whole arch-like orthopantogram. Each image was evaluated for mean dental age using Nolla's method of age estimation and was compared to the mean chronological age of children in the study group. The study was conducted to evaluate the applicability of Nolla's method of age estimation in the North Indian population.

Results: The mean dental age was found to be significantly underestimated by (1.8 \pm 5.5$)$ months in 900 children. The trend of underestimation was more in males ( $(2.5 \pm 4.2)$ months) as compared to females ((1.1 \pm 6.4$)$ months). Both sexes showed underestimation of chronological age till 14 years. However, the dental age and chronological age became similar at 14 years, and overestimation of chronological age was observed afterwards ( $p$ value $>0.001$ ).

Conclusion: Nolla's method of age estimation using radiovisiograph for mandibular second molar is a reliable method in children of North Indian origin, although it underestimates the chronological age. After the average age of 14, dental age surpassed chronological age in the study group. In addition, permanent mandibular second molar was found to be a reliable tooth for dental age estimation.
\end{abstract}

Keywords: Dental age estimation, Nolla's method, North Indian, Mandibular second molar, Radiovisiograph

\section{Background}

Estimation of age is a crucial exercise in medico-legal cases and while formulating treatment plans. Age estimation has many factors, viz., skeletal age, sexual age, chronological age (CA), and dental age (DA). Assessment of tooth development is widely being used these days for age estimation (Kırzıoğlu and Ceyhan, 2012). Teeth are considered among the most indestructible part of the body exhibiting the least turnover rate of natural structure. The nutritional, hormonal, and pathological changes have minimal effect on developing teeth in

\footnotetext{
*Correspondence: nkalraucms@yahoo.com

Department of Pedodontics and Preventive Dentistry, University College of Medical Sciences, Guru Teg Bahadur Hospital, University of Delhi, Delhi,
} Dilshad Garden 110095, India

children, making them a valuable tool for age estimation

Rachbhai 2011)

Ratiographic method is a more accurate, non-destructive, radiograph (Schmeling et al. 2010).

Dental age estimation using an orthopantogram has the advantages of a one-time exposure and very low doses of radiation with negligible proportional effect, especially when compared with other skeletal radiographic 
techniques. There is an inconsequential risk of $<1: 2,000$, 000 ( 2 million) of developing cancer from a single orthopantogram radiograph in a lifetime, and the odds of death is totally "negligible" (Whaites and Drage, 2013).

Consequently, this may justify the use of an orthopantogram as a commonly chosen radiographing technique by most age assessment methods (Demirjian et al. 1973; Kvaal et al. 1995). Notwithstanding its popularity in literature, it has approximately 10 times greater radiation exposure in comparison to intra oral periapical radiograph-radiovisiography (RVG)-making the latter a valid choice of radiography for applying Nolla's method in our study, thus following ALARA (as low as reasonably achievable) principle (White and Pharoah 2009).

Nolla's method measures calcification progression in a tooth by quantifying it objectively (Nolla 1960). A population specific assessment for Nolla's method for North Indian population may help forensic odontologists, age estimation boards, and healthcare professionals, therefore forming the rationale of this study.

\section{Materials and methods}

Children aged 10-16 years (120-192 months) of North Indian origin visiting the outpatient setting of the Department of Paedodontics and Preventive Dentistry, UCMS, and GTBH, Delhi, were screened. Those requiring routine radiographs for both diagnostic and therapeutic purposes exhibiting distinct root morphology of permanent mandibular right second molar were considered for inclusion in the study. Of these children, those presenting with history of fluorosis, bone deformity, bone diseases, history of surgery, or trauma in dentofacial region affecting growth and development were excluded from the study. The remaining children were then allotted a number, and only the ones bearing a random number (computer generated random sampling list) were finally radiographed. The above exercise was carried out on a daily basis till a figure of 900 was achieved.

A total of 900 children were subsequently selected and allotted to six groups according to their age (Table 1). The ongoing study had no bearing on the treatment protocol required and delivered for each child and was done after due approval from the Institutional Ethics Committee-Human Research (IEC-HR) of UCMS and GTBH, Delhi, with reference no. IEC-HR/2017/32/127. Informed consent was obtained from parents/guardian prior to the study. Chronological age was confirmed and recorded from the parents/guardians of the patient on the day of radiograph.

\section{Radiographic assessment}

Dental age was calculated using radiovisiograph of permanent right mandibular second molar. A radiovisiograph sensor (Vatech EzSensor Classic, IOS-U15IB, Size 1.5) duly covered with sterile sleeve was placed in the right mandibular second molar region, and the $\mathrm{x}$-ray tube was positioned at a standard $5^{\circ}$ angle focusing on the area of interest. The radiograph was exposed at a standard $60-\mathrm{kV}$ power for $0.2 \mathrm{~s}$ exposure time at $6 \mathrm{~mA}$ current. Staging in Nolla's method involves shape of the tooth rather than its dimensions; hence, radiographs were obtained by bisecting angle technique.

The soft copies of radiographs were then assessed, interpreted, and accordingly staged to obtain the dental age, using Nolla's method (Fig. 1). The stages recorded by guide, co-guide, and primary investigator were compared and the process continued till high level accuracy and confidence level were reached. Fleiss' kappa was further used to evaluate the intra and inter-investigator agreement between investigators. The mean of appropriate stage observed by each investigator was obtained and used to evaluate the dental age of tooth using the table given by Nolla (Nolla 1960). Dental age obtained was then compared with the pre-recorded chronological age. Difference was then statistically evaluated for the respective group for determining the validity and accuracy of Nolla's method.

\section{Reasons of using mandibular second molar as the tooth of choice for assessment}

The reasons for considering permanent mandibular second molar for this study were:

Table 1 Age and gender distribution of the subjects included in the study

\begin{tabular}{lllll}
\hline Group & $\begin{array}{l}\text { Age group } \\
\text { (months) }\end{array}$ & Female & Male & Total no. of subjects $(n)$ \\
\hline Group I & $120-131$ & 58 & 180 & $238(26.4 \%)$ \\
Group II & $132-143$ & 69 & 26 & $95(10.6 \%)$ \\
Group III & $144-155$ & 70 & 56 & $126(14 \%)$ \\
Group IV & $156-167$ & 109 & 27 & $136(15.1 \%)$ \\
Group V & $168-179$ & 39 & 59 & $98(10.9 \%)$ \\
Group VI & $180-192$ & 97 & 110 & $207(12.2 \%)$ \\
Total & $120-192$ & $442(49.1 \%)$ & $458(50.9 \%)$ & 900 \\
\hline
\end{tabular}




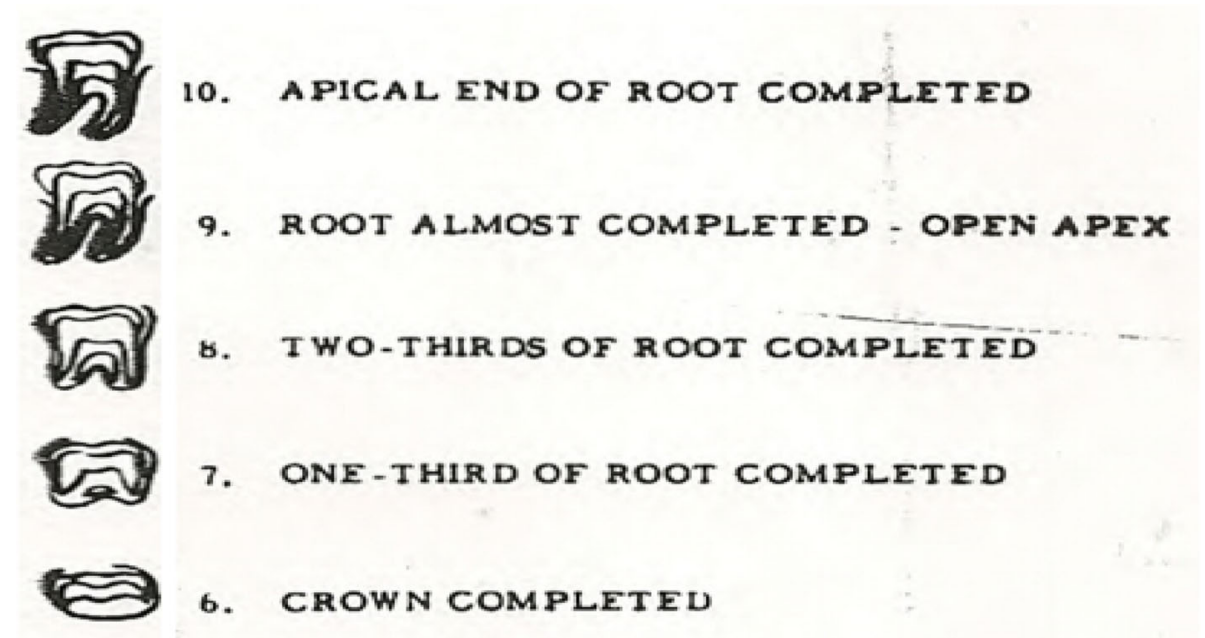

Fig. 1 Nolla's method of staging *only relevant stages were included

a) Firstly, active growth of most children extends up to the age of 16 to 17 years which coincides with the apex closure of the chosen tooth while the apex of maxillary and mandibular canines ordinarily close by 13 years of age (Saloom 2011).

b) Secondly, the third molars are the most commonly missing teeth in the human dentition, making them unreliable for age assessment.

c) Thirdly, maxillary second molar was rejected as roots of maxillary molar overlap with anatomic structures making it difficult to observe the roots with accuracy.

\section{Statistical analysis}

All data was entered in the excel sheet and was analysed using the SPSS version 20 software. A descriptive analysis was made expressing the results as percentages and frequencies. Statistical significance was considered for $p$ value $>0.001$ in all cases. Paired $t$ test was used to compare the variables at different time intervals. To assess the intra-investigator agreement and inter-investigator agreement, Fleiss' kappa was used.

\section{Result}

The mean dental age of all children was compared to mean chronological age, and the difference was analysed. The mean dental age was found to be significantly underestimated by $(1.8 \pm 5.5)$ months $(p$ value $>0.001)$. In group-wise evaluation, a significant underestimation of age was observed in group I and group II, while in group III, it was reduced to 0.5 months which was statistically insignificant. Underestimation was overcome in group IV which, however, was statistically insignificant ( $p$ value > $0.001)$. Likewise, underestimation was statistically insignificant in group V, but in group VI, the overestimation of age was observed, and the assessed dental age exceeded chronological age significantly ( $p$ value $>0.001$ ). Therefore, a significant reversal of the trend in the age groups was observed (Table 2 and Fig. 2).

The male and female populations were found to be significantly underestimated by $2.5 \pm 4.2$ and $1.1 \pm 6.4$ months, respectively ( $p$ value $>0.001$ ). Both sexes followed a similar trend; however, in group $\mathrm{V}$, overestimation of age was seen in boys by 0.06 months (Table 2).

In absolute numbers, it was observed that 50 children were found to be of exactly the same dental and chronological age. Underestimation was seen in 514 children while 336 children showed overestimation. The number of underestimated and overestimated children showing difference of less than 6 months were 363 (70.6\%) and $291(83.6 \%)$, respectively (Table 3$)$.

Furthermore, a pattern of underestimation was observed in total sample (5.41 months) in females (4.31 months) and in males (6.31 months). Similarly, pattern of overestimation was observed in total sample (3.51 months), in females (2.98 months) and in males (4.13 months) (Table 4 and Fig. 3).

It was observed that 40 children, who were exactly 16 years of age and were radiographed in their birth month incidentally, were further analysed. Among them, 94.4\% females and $90.9 \%$ males were observed to have completed tooth maturation by 16 years of age. It may be concluded that by the age of 16 years, nearly all girls and boys had completed the root development of the respective tooth.

The mean Fleiss' kappa value for intra-investigator agreement was 0.84 interpreted to be almost perfect (> 0.80 ). While Fleiss' kappa value for inter-investigator agreement was 0.78 , it was interpreted to have substantial agreement $(<0.80)$. 
Table 2 Age-wise comparison of the mean dental age (using Nolla's method) and mean chronological age in all the six age groups to understand the trend of growth in boys compared to girls as well as to the entire group

\begin{tabular}{|c|c|c|c|c|c|c|c|c|c|c|c|c|}
\hline \multirow[b]{2}{*}{ Group } & \multicolumn{4}{|c|}{ All subjects } & \multicolumn{4}{|c|}{ Female subjects } & \multicolumn{4}{|c|}{ Male subjects } \\
\hline & $\begin{array}{l}\text { No. of } \\
\text { subjects } \\
(n)\end{array}$ & $\begin{array}{l}\mathrm{DA} \\
\text { (months) } \\
\text { mean } \pm \mathrm{SD}\end{array}$ & $\begin{array}{l}\mathrm{CA} \\
\text { (months) } \\
\text { mean } \pm \mathrm{SD}\end{array}$ & $\begin{array}{l}\text { DA-CA } \\
\text { (months) } \\
\text { mean } \pm S D\end{array}$ & $\begin{array}{l}\text { No. of } \\
\text { subjects } \\
\text { (n) }\end{array}$ & $\begin{array}{l}\mathrm{DA} \\
\text { (months) } \\
\text { mean } \pm \mathrm{SD}\end{array}$ & $\begin{array}{l}\mathrm{CA} \\
\text { (months) } \\
\text { mean } \pm S D\end{array}$ & $\begin{array}{l}\text { DA-CA } \\
\text { (months) } \\
\text { mean } \pm S D\end{array}$ & $\begin{array}{l}\text { No. of } \\
\text { subjects } \\
(n)\end{array}$ & $\begin{array}{l}\mathrm{DA} \\
\text { (months) } \\
\text { mean } \pm \mathrm{SD}\end{array}$ & $\begin{array}{l}\mathrm{CA} \\
\text { (months) } \\
\text { mean } \pm S D\end{array}$ & $\begin{array}{l}\text { DA-CA } \\
\text { (months) } \\
\text { mean } \pm S D\end{array}$ \\
\hline $\begin{array}{l}\text { Group } \\
\text { l }\end{array}$ & 238 & $115.9 \pm 7.7$ & $122.9 \pm 3.3$ & $-6.9 \pm 5.5$ & 58 & $117.9 \pm 7.1$ & $123.7 \pm 3.7$ & $-5.9 \pm 4.5$ & 180 & $115.3 \pm 7.9$ & $122.6 \pm 3.1$ & $-7.4 \pm 5.9$ \\
\hline $\begin{array}{l}\text { Group } \\
\|\end{array}$ & 95 & $134.2 \pm 4.8$ & $136.5 \pm 2.9$ & $-2.3 \pm 4.1$ & 69 & $133.6 \pm 4.4$ & $136.3 \pm 2.4$ & $-2.7 \pm 4.2$ & 26 & $135.9 \pm 5.6$ & $137.1 \pm 3.9$ & $-1.3 \pm 3.6$ \\
\hline $\begin{array}{l}\text { Group } \\
\text { III }\end{array}$ & 126 & $148.8 \pm 5.1$ & $149.4 \pm 3.7$ & $-0.6 \pm 3.3$ & 70 & $149.0 \pm 5.5$ & $149.7 \pm 3.7$ & $-0.7 \pm 3.4$ & 56 & $148.7 \pm 4.6$ & $149.1 \pm 3.7$ & $-0.4 \pm 3.3$ \\
\hline $\begin{array}{l}\text { Group } \\
\text { IV }\end{array}$ & 136 & $162.5 \pm 5.6$ & $162.3 \pm 3.7$ & $0.2 \pm 3.7$ & 109 & $162.7 \pm 5.7$ & $162.6 \pm 3.7$ & $0.2 \pm 3.6$ & 27 & $161.7 \pm 5.4$ & $161.3 \pm 3.4$ & $0.4 \pm 4.0$ \\
\hline $\begin{array}{l}\text { Group } \\
\text { V }\end{array}$ & 98 & $172.5 \pm 5.8$ & $173.1 \pm 3.6$ & $-0.6 \pm 3.7$ & 39 & $169.2 \pm 5.4$ & $170.9 \pm 2.6$ & $-1.7 \pm 4.0$ & 59 & $174.7 \pm 4.6$ & $174.6 \pm 3.4$ & $0.1 \pm 3.6$ \\
\hline $\begin{array}{l}\text { Group } \\
\mathrm{Vl}\end{array}$ & 207 & $189.9 \pm 6.7$ & $188.1 \pm 3.9$ & $1.8 \pm 4.1$ & 97 & $190.9 \pm 2.9$ & $189.5 \pm 2.4$ & $1.4 \pm 2.4$ & 110 & $189.1 \pm 8.8$ & $186.9 \pm 4.5$ & $2.2 \pm 5.3$ \\
\hline Total & 900 & $\begin{array}{l}152.7 \pm \\
28.5\end{array}$ & $\begin{array}{l}154.4 \pm \\
24.9\end{array}$ & $-1.8 \pm 5.5$ & 442 & $\begin{array}{l}156.9 \pm \\
24.4\end{array}$ & $\begin{array}{l}157.9 \pm \\
22.1\end{array}$ & $-1.1 \pm 4.2$ & 458 & $\begin{array}{l}148.6 \pm \\
31.5\end{array}$ & $\begin{array}{l}151.1 \pm \\
27.0\end{array}$ & $-2.5 \pm 6.4$ \\
\hline
\end{tabular}

The collected data helped us add sub-stages to Nolla's tooth stages for a more objective radiographic interpretation. However, these findings could not be standardised due to the smaller sample size (Fig. 4).

\section{Discussion}

The degree of maturation of different tissue systems helps determine the physiological age of a person. Tooth development shows less variability than other developmental features and also low variability in relation to chronological age (Demirjian et al. 1973). Radiographs of the dentition can be used to determine the stage of dental development of the teeth from initial mineralization of a tooth, crown formation, to root apex maturation.

Nolla's method is based on radiographic assessment and regarded as one of the most commonly used and easy to apply dental age estimation method. The advantage of using intraoral periapical radiograph (radiovisiograph) in Nolla's method lies in its familiarity, accessibility, reproducibility, and ease of communication for dental surgeons. The tools incorporated in the software of radiovisiographs further increase the value of interpretation.

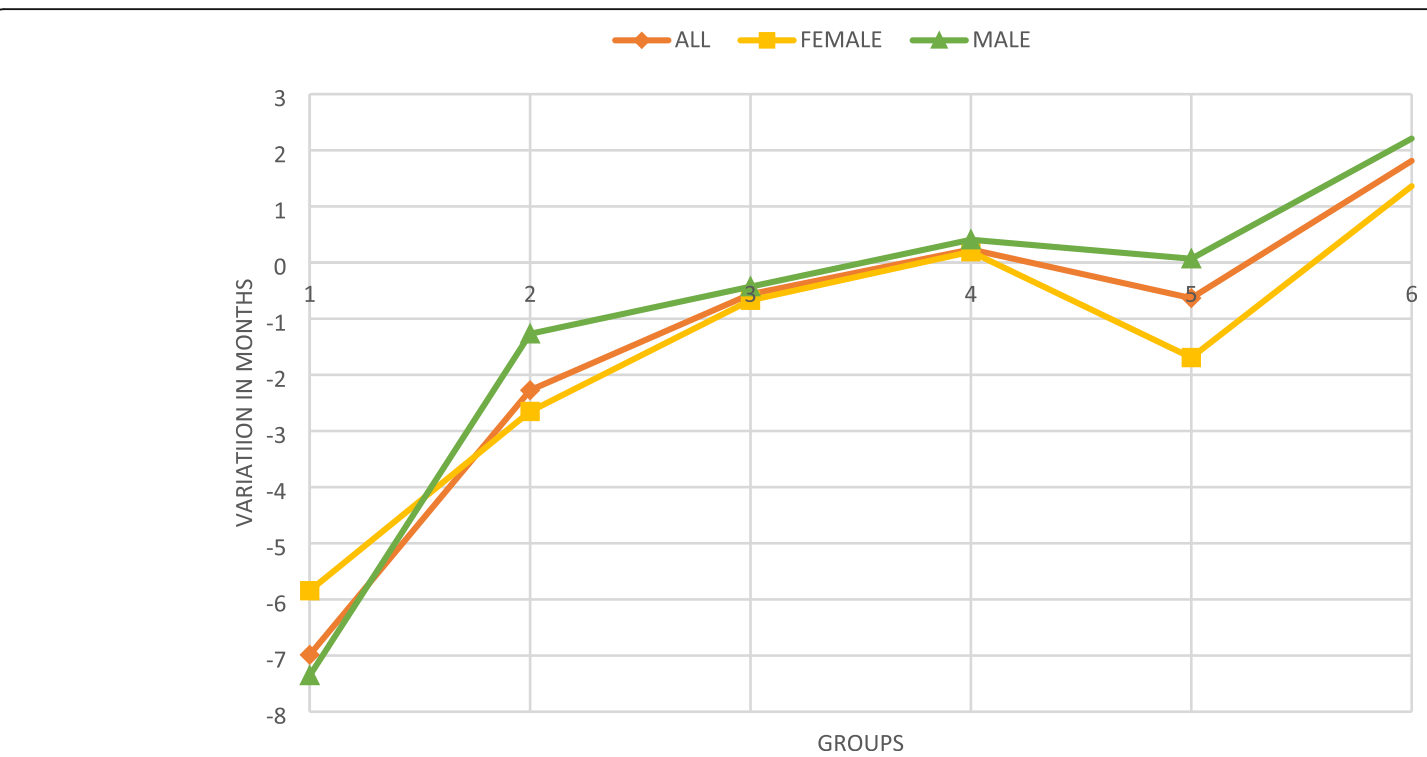

Fig. 2 Graph showing age-wise comparison of the differences of the mean dental age (using Nolla's method) and mean chronological age in all the subjects in our study 
Table 3 Incremental pattern to understand the pattern of underestimation and overestimation in development amongst our subjects

\begin{tabular}{lll}
\hline $\begin{array}{l}\text { Period of variation in dental age and } \\
\text { chronological age }\end{array}$ & $\begin{array}{l}\text { No. of subjects in whom underestimation of age } \\
\text { was observed }(n)\end{array}$ & $\begin{array}{l}\text { No. of subjects in whom underestimation of age } \\
\text { was observed }(n)\end{array}$ \\
\hline$<3$ months & $136(15.11 \%)$ & $172(19.11 \%)$ \\
$3-6$ months & $227(25.22 \%)$ & $119(13.22 \%)$ \\
$6-8$ months & $51(5.6 \%)$ & $35(3.9 \%)$ \\
$>8$ months & $100(11.1 \%)$ & $10(1.1 \%)$ \\
Total & $514(57.1 \%)$ & $336(37.3 \%)$ \\
\hline
\end{tabular}

PS: does not include 50 subjects having exact chronological age and dental age

In literature, several studies have been performed previously using Nolla's method of age estimation to assess dental age in their specific population or region in Bangladesh, England (Maber et al. 2006), Brazil (Kurita et al. 2007), Turkey (Kırzıoğlu and Ceyhan, 2012), Malaysia (Kumaresan et al. 2016), and East Turkey (Miloglu et al. 2011).

In most of the studies, it was found that Nolla's method of age estimation had better accuracy (Rai 2008; Kumaresan et al. 2016; Mohammed et al. 2015) while contrary results were seen in few studies (Maber et al. 2006) as well. In a study conducted in the North Indian population, high correlation was found between skeletal age (assessed from middle phalanx of the third finger and hand-wrist radiographs) and dental age (assessed from Nolla's method) in both sexes in 12-14 years age group (Bala et al. 2010). Conversely, in another study, it was observed that Demirjian's method was better when compared to Nolla's method in North the Indian population because of its applicability to all the age groups as Nolla's method had limited utility in the younger age group only (Sinha et al., 2014).
In the present study, it was observed that the age of the subjects was significantly underestimated by $(1.8 \pm$ 5.5 ) months ( $p$ value $>0.001)$. Since the difference was of only 1.8 months clinically, it may be safely concluded that age estimation using Nolla's method seemed to be precise. In most of the studies (Kurita et al. 2007; Miloglu et al. 2011; Kırzıoğlu and Ceyhan, 2012), dental age was lagging behind chronological age supporting our findings while in few studies (Kumaresan et al. 2016; Mohammed et al. 2015), dental age was found ahead of the chronological age.

On comparing between the two sexes, it was observed that dental age of the subjects significantly lagged behind the chronological age by $(1.1 \pm 6.4)$ months in females and $(2.5 \pm 4.2)$ months in males ( $p$ value $>0.001)$ (Table 2) supported by various studies (Kurita et al. 2007). Alternatively, few studies (Kumaresan et al. 2016; Mohammed et al. 2015) have shown advanced dental age.

Moreover, it was seen that Nolla's method was more precise for females than males in our study while contrary results was found by Kirzioglu and Ceyhan (Kırzığlu and Ceyhan, 2012). Nolla's findings (Nolla 1960)

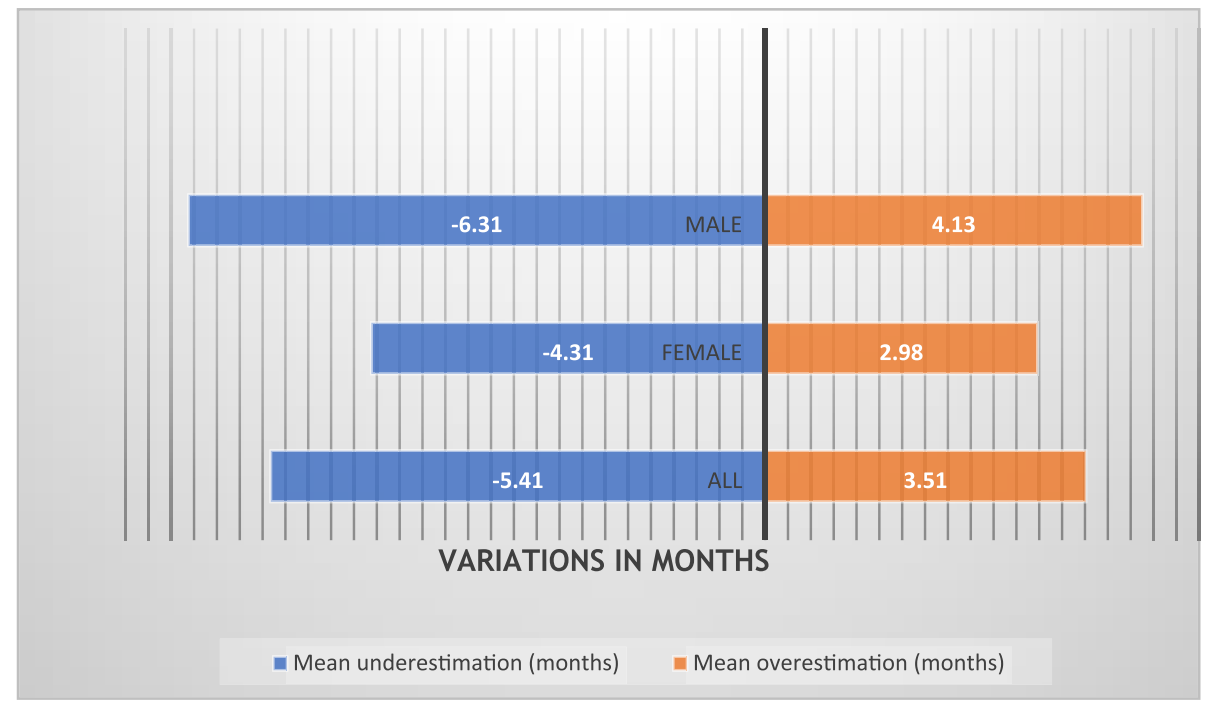

Fig. 3 Graph depicting mean underestimation and overestimation amongst our subjects (in months) 


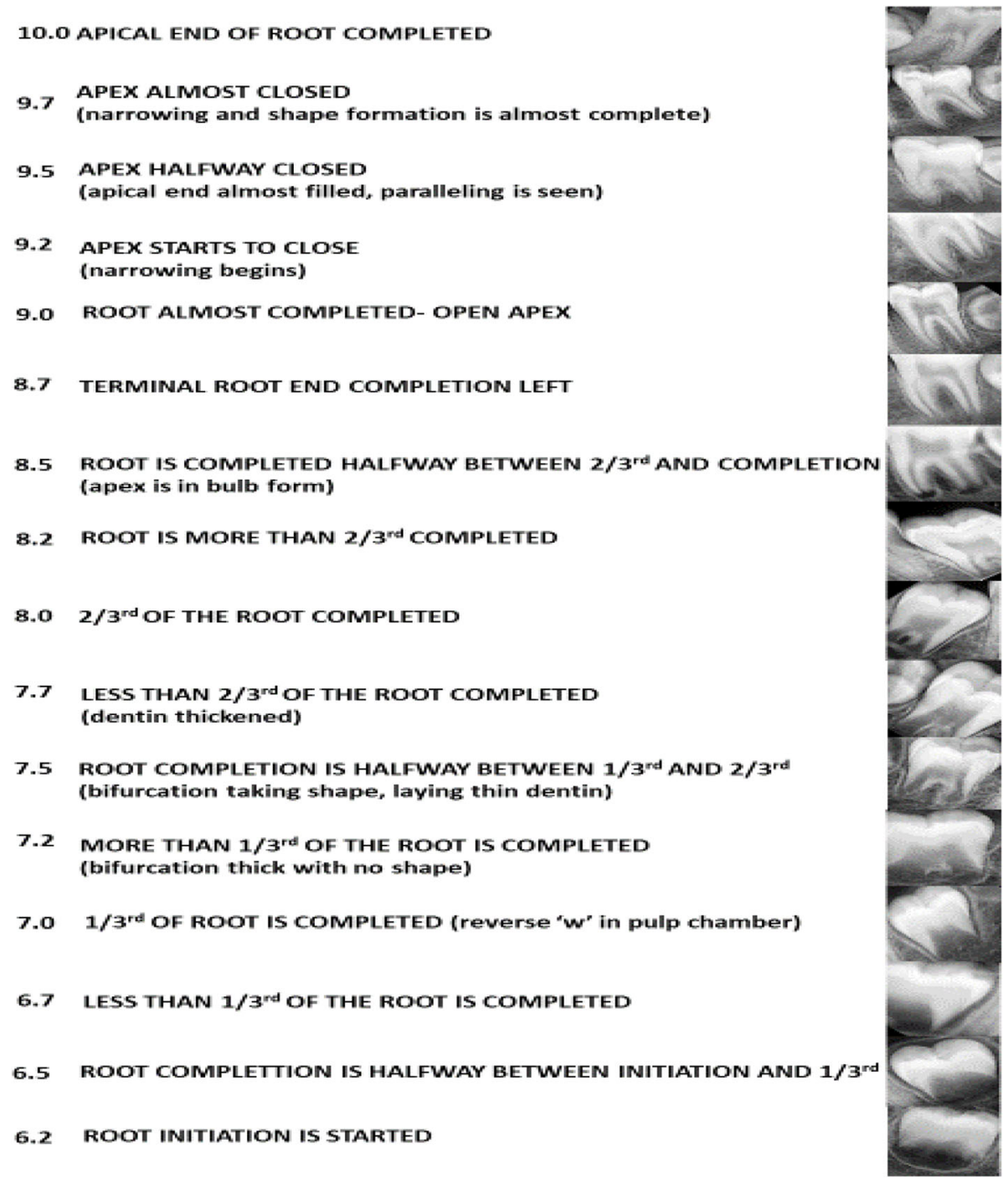

Fig. 4 Proposed substages for Nolla's staging method drawn out from the study on North Indian population\

were likewise reflected in our study that revealed that females achieved dental development earlier than males.

In our study, in subjects from the age of 120 to 155 months, underestimation of age was observed with maximum underestimation in group I, i.e., 6.98 months. The underestimation was also evident in group II and group III which was overcome in group IV. In group V, the underestimation was evident but not statistically significant while in group VI, the overestimation of age was observed which was statistically significant ( $p$ value > 0.001) (Table 2).

Nonetheless, underestimation was observed in all the groups in certain studies (Kurita et al. 2007; Miloglu et al. 2011). Mohammed et al. conducted similar studies in South Indian population and found results contrary to our study owing to different ethnicities of their study sample (Mohammed et al. 2015).

While comparing variation in chronological age and estimated dental age in both female and male subjects, it was found that subjects with variation 0-6 months were 358 and 346 in number, respectively. Thus, 704 out of 900 subjects $(78.22 \%)$ exhibited this variation within 6 months (Table 3 ). In a study performed by Sinha et al., 181 subjects out of 300 subjects, i.e., $60.3 \%$ subjects were showing variation with more than 6 months (Sinha et al. 2014).

The mean underestimation and overestimation amongst all the subjects were found to be 5.41 months and 3.51 months, respectively. These values for boys were 6.31 months and 4.31 months and for girls were 
Table 4 Mean underestimation and overestimation in development amongst our subjects

\begin{tabular}{lll}
\hline Subjects & $\begin{array}{l}\text { Mean underestimation in } \\
\text { months (no. of subjects) }\end{array}$ & $\begin{array}{l}\text { Mean overestimation in } \\
\text { months (no. of subjects) }\end{array}$ \\
\hline Total & $5.41(514)$ & $3.51(336)$ \\
Female & $4.31(231)$ & $2.98(182)$ \\
Male & $6.31(283)$ & $4.13(154)$ \\
\hline
\end{tabular}

4.31 months and 2.98 months, respectively (Table 4 and Graph 2). This implies that observed dental age of girls remained closer to Nolla's age estimation than boys.

\section{Conclusion}

Nolla's method of age estimation is a reliable method in 10-16 years old children of North Indian origin. It underestimates the chronological age in total sample population and also when evaluated in relation to sex. Underestimation of age in North Indian origin children was observed in initial years when compared to Nolla's norms but it gradually accelerated and consequently surpassed the chronological age. Permanent mandibular second molar was found to be a reliable tooth for dental age estimation. More females were found to have completed tooth maturation by 16 years of age.

\section{Abbreviations}

RVG: Radiovisiograph; DA: Dental age; CA: Chronological age; ALARA: As low as reasonably achievable

\section{Acknowledgements}

I would like to thank all the staff of the department and radiograph technicians.

\section{Authors' contributions}

HVS was the primary investigator of the study and collected the data, evaluated the radiographic staging, and wrote and revised all stages of the manuscript. NK was the evaluator of radiographic staging and played major contribution in manuscript writing and planning of manuscript. RT was also the evaluator to radiographic staging and checked and revisited all manuscript drafts including the final version. AK rechecked the collected data and helped with the statistical analysis. All the authors and co-authors contributed significantly in the manuscript preparation. The manuscript was read and approved by all authors. The authors agree to copyright transfer in case of manuscript acceptance for publication.

\section{Funding}

This research received no specific grants from any funding agency in public, commercial and not-for-profit sectors.

\section{Availability of data and materials}

The datasets generated and/or analysed during the current study are available from the corresponding author on reasonable request.

\section{Ethics approval and consent to participate}

This was done after due approval from the Institutional ethics committeehuman research (IEC-HR) of UCMS and GTBH, Delhi with reference no. IEC$\mathrm{HR} / 2017 / 32 / 127$

\section{Consent for publication}

N/A

\section{Competing interests}

The authors declare that they have no competing interests.

Received: 3 February 2020 Accepted: 2 July 2020

Published online: 27 July 2020

\section{References}

Babshet M, Acharya AB, Naikmasur VG (2010) Age estimation in Indians from pulp/tooth area ratio of mandibular canines. Forensic Sci Int. 197(1-3):125$1 \mathrm{e} 1$

Bala M, Pathak A, Jain RL (2010) Assessment of skeletal age using MP 3 and hand-wrist radiographs and its correlation with dental and chronological ages in children. J Indian Soc Pedod Prev Dent. 28:95-99

Demirjian A, Goldstein H, Tanner JM (1973) A new system of dental age assessment. Human Biol 45:211-227

Kırzıoğlu Z, Ceyhan D (2012) Accuracy of different dental age estimation methods on Turkish children. Forensic Sci Int 216:61-67

Kumaresan R, Cugati N, Chandrasekaran B, Karthikeyan P (2016) Reliability and validity of five adiographic dental-age estimation methods in a population of Malaysian children. J Inves Clin Dent. 7:102-109

Kurita LM, Menezes AV, Casanova MS, Haiter-Neto F (2007) Dental maturity as an indicator of chronological age: radiographic assessment of dental age in a Brazilian population. J Appl Oral Sci. 15:99-104

Kvaal SI, Kolltveit KM, Thomsen IO, Solheim T (1995) Age estimation of adults from dental radiographs. Forensic Sci Int 74:175-185

Maber M, Liversidge HM, Hector MP (2006) Accuracy of age estimation of radiographic methods using developing teeth. Forensic Sci Int 159:68-73

Miloglu O, Celikoglu M, Dane A, Cantekin K, Yilmaz AB (2011) Is the assessment of dental age by the Nolla method valid for eastern Turkish children? J Forensic Sci 56:1025-1028

Mohammed RB, Sanghvi P, Perumalla KK, Srinivasaraju D, Srinivas J, Kalyan US et al (2015) Accuracy of four dental age estimation methods in southern Indian children. J Clin Diag Res 9:1-8

Nolla CM (1960) The development of permanent teeth. J Dent Child 27:254-266

Panchbhai AS (2011) Dental radiographic indicators, a key to age estimation. Dentomaxillofacial Radiol 40(4):199-212

Rai B (2008) The evaluation of two radiographic methods for age determination of children in an Indian population. J Forensic Odontostomatol 27(2):30-3

Saloom HF (2011) Detection of skeletal maturity using periapical radiographs (a study on Iraqi growing sample). J Bagh Coll Dentistry 23(sp. issue):155-161

Schmeling A, Olze A, Reisinger W, Geserick G (2010) Age estimation of living people undergoing criminal proceedings. Lancet 358:89-90

Sinha S, Umapathy D, Shashikanth MC, Misra N, Mehra A, Singh AK (2014) Dental age estimation by Demirjian's and Nolla's method: a comparative study among children attending a dental college in Lucknow (UP). J Indian Acad Oral Med Radiol 26:279-286

Whaites E, Drage N (5th eds) (2013). Essentials of dental radiography and radiology. Elsevier Health Sciences.

White SC, Pharoah MJ (6th eds) (2009) Oral radiology: principles and interpretation. Mosby, St. Louis, Missouri.

\section{Publisher's Note}

Springer Nature remains neutral with regard to jurisdictional claims in published maps and institutional affiliations. 